\title{
Euphornin L promotes lipid clearance by dual regulation of LDLR and PCSK9
}

\author{
HUIHUI LI ${ }^{1,2}$, JUN LI $^{1,2}$, XIANJING ZHANG ${ }^{1,2}$, JIAOMENG LI ${ }^{1,2}$, \\ CONG XI ${ }^{1,2}$, WENQIONG WANG ${ }^{1,2}$, YOULI LU ${ }^{3,4}$ and LIJIANG XUAN ${ }^{1,2}$
}

\author{
${ }^{1}$ State Key Laboratory of Drug Research, Shanghai Institute of Materia Medica, Chinese Academy \\ of Sciences, Shanghai 201203; ${ }^{2}$ University of Chinese Academy of Sciences, Beijing 100049; \\ ${ }^{3}$ Central Laboratory, Shanghai Xuhui Central Hospital/Zhongshan-Xuhui Hospital, Fudan University, \\ Shanghai 200031; ${ }^{4}$ Shanghai Clinical Research Center, Chinese Academy of Sciences, Shanghai 200031, P.R. China
}

Received May 4, 2019; Accepted March 24, 2021

DOI: $10.3892 /$ etm.2021.10817

\begin{abstract}
Our previous study identified euphornin L as an active lipid-lowering compound in high-fat diet-fed Golden Syrian hamsters. The aim of the present study was to investigate the mechanisms underlying the lipid-lowering effects of euphornin L. Euphornin L in HepG2 cells was assessed via DiI-LDL update assays and found to increase LDL-update and LDLR protein levels. RNA interference assays demonstrated that its LDL-update effects were LDLR-dependent. Dual luciferase reporter and mRNA stability assays revealed that euphornin L had little effect on LDLR mRNA transcription but lengthened the half-life of $L D L R$ mRNA by activating ERK protein in cells. Euphornin L decreased the secretion of PCSK9 protein and alleviated PCSK9-mediated LDLR protein degradation. In vivo experiments in hamsters, which were treated with euphornin $\mathrm{L}(30 \mathrm{mg} / \mathrm{kg} /$ day) for 3 weeks, confirmed these findings. LDLR protein levels in liver tissue were upregulated, while PCSK9 protein levels in serum were downregulated. Altogether, the present study demonstrated that euphornin L increased LDLR protein levels by dual regulation of $L D L R$ mRNA and PCSK 9 protein, and represented an active compound for lipidlowering drug development.
\end{abstract}

Correspondence to: Professor Lijiang Xuan, State Key Laboratory of Drug Research, Shanghai Institute of Materia Medica, Chinese Academy of Sciences, 501 Haike Road, Shanghai 201203, P.R. China E-mail: ljxuan@simm.ac.cn

Abbreviations: LDL, Low density lipoprotein; LDL-C, Low density lipoprotein-cholesterol; LDLR, LDL receptor; SRE1, sterol responsive element 1; ARE, adenosin and uridine-rich element; PCSK9, Proprotein convertase subtilisin/kexin type 9

Key words: euphornin L, lipid-lowering activity, low density lipoprotein receptor, proprotein convertase subtilisin/kexin type 9, extracellular signal-regulated kinase protein, secretion

\section{Introduction}

Low density lipoprotein cholesterol (LDL-C) has been considered a key predictor for cardiovascular disease, which is at present the leading cause of mortality and morbidity worldwide (1-3). Circulating LDL is mainly cleared by the LDL receptor (LDLR) on the cell membrane of hepatocytes. The mature LDLR is a transmembrane glycoprotein of 839 amino acids, with five major structural domains: the ligand-binding domain (LBD); an EGF precursor homology domain, which includes the EGF-A domain, the EGF-B domain, a 6-bladed $\beta$-propeller and the EGF-C domain; an O-linked sugar domain; a transmembrane domain; and a cytoplasmic tail $(4,5)$. The LDL particles are recognized and bound by the LBD of LDLR and then internalized by endocytosis. At the low $\mathrm{pH}$ found in endosomes, the LDLR/LDL complex dissociates and LDLR returns to the cell surface, while the released LDL proceeds to lysosomes and is degraded (6-8). Therefore, elevation of LDLR protein has been the main strategy to reduce LDL-C (9).

The expression of LDLR protein is tightly regulated at the transcriptional, post-transcriptional and post-translational levels. In hepatocytes, the transcription of $L D L R$ is negatively regulated by cellular cholesterol through the sterol responsive element 1 (SRE1) motif located in the promoter region of the $L D L R$ gene (10). When the cellular cholesterol level is low, SRE1 binding proteins, which are located in the endoplasmic reticulum (ER) membrane, are activated by two-step proteolytic cleavage and released into the nucleus to bind with the SRE1 motif, resulting in the activation of $L D L R$ transcription (11). However, the newly synthesized $L D L R$ mRNA is short-lived because of the three adenosine and uridine-rich elements, AU-rich elements (AREs) in the $3^{\prime}$ untranslated region (UTR) of $L D L R$ mRNA $(12,13)$. The half-life of $L D L R$ mRNA is $\sim 30 \mathrm{~min}$ (12). The activation of ERK protein has been found to be involved in $L D L R$ mRNA stabilization at the post-transcriptional level (4,14-16).

Proprotein convertase subtilisin/kexin type 9 (PCSK9) protein, a secretory protein mainly expressed and secreted by the liver tissues, functions at the post-translational level by promoting the degradation of LDLR protein (17-19). PCSK9 is a single peptide and includes a prodomain, a catalytic domain 
and a C-terminal domain (CTD) (20). Following autocleavage between Gln-152 and Ser-153, the prodomain remains noncovalently attached to the catalytic domain (5). PCSK9 serves as a natural eliminator of LDLR by binding to the EGF-A extracellular domain of LDLR protein, triggering its degradation in lysosomes and thus increasing the level of circulating LDL-C (21). The first humanized PCSK9 antibodies, alirocumab and evolocumab, were approved by the US FDA in 2015 and introduced a significant reduction in cardiovascular death $(22,23)$. However, the daunting cost and the troublesome subcutaneous administration are evident drawbacks for the two antibodies. Therefore, small, orally available compounds that act as PCSK9 regulators and have excellent efficacy and low cost are desired.

Our previous study identified euphornin L, a jatrophane macrocyclic diterpenoid extracted from Euphorbia helioscopia, as an active compound for promoting LDL uptake and improving LDLR protein levels in HepG2 cells. An in vivo study showed that treatment with euphornin $\mathrm{L}$ in high-fat diet-fed Golden Syrian hamsters significantly reduced serum LDL-C by $38.9 \%$ (24). The current study investigated the mechanisms underlying the lipid-lowering effects of euphornin L, which is designated C21 in this article, in HepG2 cells.

\section{Materials and methods}

Materials and reagents. Dulbecco's modified Eagle's medium (DMEM; cat. no. SH30243.01) was purchased from HyClone (Cytiva). Fetal bovine serum (FBS; cat. no. 10091-148) and Lipofectamine ${ }^{\circledR} 3000$ (cat. no. L3000-015) were obtained from Thermo Fisher Scientific, Inc. Atorvastatin calcium salt trihydrate (Atorvastatin; cat. no. PZ0001; $\geq 98 \%$-HPLC), Phorbol 12-myristate 13 -acetate (PMA; cat. no. P1585; $\geq 99 \%$-HPLC) and DMSO (cat. no. D2650; $\geq 99.7 \%$-HPLC) were purchased from Sigma-Aldrich; Merck KGaA.

Rabbit anti-human LDLR monoclonal antibody (cat. no.; ab52818; 1:1,000) and rabbit anti-human PCSK9 monoclonal antibody (cat. no.; ab181142; 1:2,000) were purchased from Abcam. Rabbit anti-human/hamster p-ERK polyclonal antibody (cat. no. 9101; 1:2,000), rabbit anti-human/hamster ERK monoclonal antibody (cat. no. 4695; 1:2,000) and mouse antihuman/hamster $\beta$-actin monoclonal antibody (cat. no. 4967, 1:3,000) were purchased from Cell Signaling Technology, Inc. Rabbit anti-hamster LDLR polyclonal antibody (cat. no. 3839; 1:2,000) was purchased from BioVision, Inc. (cat. no. 3839; 1:2,000). Rabbit anti-hamster PCSK9 polyclonal antibody was a kind gift from laboratory of Professor Jingwen Liu (Department of Veterans' Affairs, Palo Alto Health Care System).

Hamster serum triglyceride (cat. no. CH0101151; Maccura Biotechnology Co., Ltd.), total cholesterol (cat. no. L873; Shino-Test Corporation), high density lipoprotein cholesterol (cat. no. AQ986; FujiFilm Wako Pure Chemical Corporation), LDL-C (cat. no. AG251; FujiFilm Wako Pure Chemical Corporation) and the activities of aspartate aminotransferase (AST; cat. no. A871; Shino-Test Corporation) and alanine aminotransferase (ALT; cat. no. B871; Shino-Test Corporation) were measured with commercial kits and the Hitachi 7020 autoanalyzer (Hitachi, Ltd.).
Compound extraction and isolation. Euphorbia helioscopia was harvested in March 2015 from Hebei (China) and identified by Professor Heming Yang (Shanghai Institute of Materia Medica, China). A voucher specimen (no. SIMM 238) has been deposited in the Herbarium of Shanghai Institute of Materia Medica, Chinese Academy of Sciences.

The air-dried, powdered E. helioscopia (10 kg) was extracted three times with $95 \%$ aqueous ethanol (EtOAc) at room temperature. A crude extract (934 g) was obtained after concentration in vacuo, which was dissolved in water (2l) and then extracted with EtOAc to get the EtOAc-soluble fraction (377 g). The latter was subjected to a silica gel column and eluted with petroleum ether-acetone (100:0-0:100) to obtain eight fractions A-H. Fractions D1-D9 were yield from fraction $\mathrm{D}$ after eluting with petroleum ether (PE)/EtOAc (20:1 to 1:1). Sephadex LH-20 gel column was then used to get two fractions (D9A-D9B) from fraction D9. Then fractions D9B1-D9B3 were acquired by eluting with $\mathrm{PE} / \mathrm{EtOAc}$ (8:1-3:1) from fraction D9B. Fraction D9B2 was then put into a RP-C18 column methanol $(\mathrm{MeOH}) / \mathrm{H}_{2} \mathrm{O}, 75: 25$ to $\left.95: 5\right)$ to obtain fractions D9B2A-D9B2D, among which C21 (812.5 mg) was harvested from fraction D9B2C by preparative HPLC $\left(\mathrm{MeOH} / \mathrm{H}_{2} \mathrm{O}\right.$, 85:15). C21 was identified as Euphornin L by comparison of the ${ }^{13} \mathrm{C}$ NMR spectra with the data reported previously (25).

Euphornin L (C21): ${ }^{13} \mathrm{C}$ NMR $\left(100 \mathrm{MHz}, \mathrm{CDCl}_{3}\right) \delta: 15.8$, 17.1, 20.3, 20.6, 21.2, 21.3, 21.4, 22.6, 22.8, 32.4, 36.6, 39.7, $39.8,41.9,43.6,73.2,74.0,74.0,83.0,92.2,121.3,128.4(\mathrm{x} 2)$, 129.4, 129.4 (x2), 130.5, 132.7, 133.0, 136.0, 166.2, 169.4, 169.6, 170.0, 170.5. HR-ESI-MS: $m / z 565.2770(\mathrm{M}+\mathrm{Na})^{+}$(calculated $^{-}$ for $\left.\mathrm{C}_{3} 1 \mathrm{H}_{42} \mathrm{O}_{8} \mathrm{Na}, 565.2772\right)$. HPLC analysis: $\mathrm{MeOH}-\mathrm{H}_{2} \mathrm{O}(0.1 \%$ formic acid; 90:10), eluted at $3.52 \mathrm{~min}, 97.77 \%$ purity.

Cell culture. The liver cancer cell line HepG2 was obtained from the American Type Culture Collection (cat. no. HB-8065) and maintained in DMEM with $10 \%$ FBS (v/v) and incubated under a humidified atmosphere of $95 \% \mathrm{O}_{2}$ and $5 \% \mathrm{CO}_{2}$ at $37^{\circ} \mathrm{C}$. Cells were sub-cultured once every two days. Cells within 4 to 11 passages were used for experiments.

Cell viability analysis. HepG2 cells were seeded in 96-well plates $\left(1.0 \times 10^{4}\right.$ cells/well) for $24 \mathrm{~h}$ prior to treatment with indicated concentrations of C21. After another $24 \mathrm{~h}$, cell viability was detected with Enhanced Cell Counting Kit-8 (cat. no. C0043; Beyotime Institute of Biotechnology) according to the manufacturer's instructions.

Lipoprotein isolation and DiI-LDL preparation. Human plasma $(200 \mathrm{ml})$ was obtained from Shanghai Xuhui Central Hospital, China (healthy donors, $n=4$, male, 20-40 years old), after informed consent and approval by the Ethics Committee of Shanghai Xuhui Central Hospital (approval no. 2018-038). The procedures conformed to the principles outlined in the Declaration of Helsinki (26). LDL and lipoprotein-deficient serum (LPDS) were separated from the pooled plasma by ultracentrifugation. Briefly, density of the pooled plasma was adjusted to $1.019 \mathrm{~g} / \mathrm{ml}$ with $\mathrm{NaBr}$ before ultracentrifugation at $4^{\circ} \mathrm{C}, 250,000 \mathrm{x} \mathrm{g}$ for $4 \mathrm{~h}$. After removing the first layer of chylomicron and VLDL, the density of the remaining part was adjusted to $1.063 \mathrm{~g} / \mathrm{ml}$ with $\mathrm{NaBr}$ before ultracentrifugation at $4^{\circ} \mathrm{C}, 250,000 \mathrm{x} \mathrm{g}$ for $24 \mathrm{~h}$. The resulting first layer was 
LDL. After removing LDL, density of the remaining part was adjusted to $1.21 \mathrm{~g} / \mathrm{ml}$ with $\mathrm{NaBr}$ before ultracentrifugation at $4^{\circ} \mathrm{C}, 250,000 \mathrm{x}$ for $48 \mathrm{~h}$; the bottom layer was LPDS. LDL and LPDS were dialyzed in dialysis buffer and PBS for $24 \mathrm{~h}$ and $48 \mathrm{~h}$, respectively. LDL was then labeled with the fluorescent probe 1, 1'-dioctadecyl-3, 3, 3', 3'-tetramethylindocarbocyanine perchlorate (DiI; Biotium) as previously described, with some modifications (27). Briefly, DiI was dissolved in DMSO $(15 \mathrm{mg} / \mathrm{ml})$ and added into the LDL/LPDS mixture $(1: 2 \mathrm{v} / \mathrm{v})$ to a final concentration of $300 \mathrm{mg} \mathrm{DiI} / \mathrm{mg}$ LDL protein and incubated for $18 \mathrm{~h}$ at $37^{\circ} \mathrm{C}$. Density of the mixture was adjusted to $1.063 \mathrm{~g} / \mathrm{ml}$ with $\mathrm{NaBr}$ before ultracentrifugation at $10^{\circ} \mathrm{C}$, $250,000 \times \mathrm{g}$ for $24 \mathrm{~h}$ to obtain the first layer of DiI-labeled LDL (DiI-LDL), followed by dialyzing in dialysis buffer and PBS for 24 and $48 \mathrm{~h}$, respectively. The obtained DiI-LDL was sterilized using $0.45 \mu \mathrm{m}$ filters (EMD Millipore).

DiI-LDL uptake assay. DiI-LDL uptake assays were conducted as described previously (27), with minor modifications. Briefly, HepG2 cells were seeded in 24-well plates. At $12 \mathrm{~h}$ later, the culture medium was changed to $2 \%$ LPDS DMEM (v/v). After incubation for $24 \mathrm{~h}$, the drugs were added into the medium and incubated with cells for another $24 \mathrm{~h}$. Then the culture medium was changed to DiI-LDL DMEM $(20 \mu \mathrm{g} / \mathrm{ml})$ and incubated for $3 \mathrm{~h}$ at $37^{\circ} \mathrm{C}$ in the dark. Subsequently, the cells were rinsed twice with ice-cold PBS buffer containing $0.4 \%$ albumin (Sigma-Aldrich; Merck $\mathrm{KGaA}$ ) and washed twice with ice-cold PBS buffer. Then, $500 \mu \mathrm{l}$ of isopropanol was added into each well followed by a 20 -min incubation in the dark at room temperature with constant shaking. Aliquots $(200 \mu \mathrm{l})$ were used for fluorescence detection with SpectraMax M2e Microplate Reader at 520-578 nm (Molecular Devices, LLC).

Western blot analysis of proteins in hamster liver tissues and in HepG2 cells. Western blotting with HepG2 cell lysates was described previously (24). HepG2 cells were cultured in 6 -well plates. After $12 \mathrm{~h}$, the culture medium was changed to $2 \%$ LPDS DMEM (v/v). Following incubation for $24 \mathrm{~h}$, the drugs were added into the medium and incubated with cells for another $24 \mathrm{~h}$. The cells were washed three times with ice-cold PBS buffer and total cellular proteins were extracted using $100 \mu \mathrm{l} /$ well lysis buffer containing protease and phosphatase inhibitor cocktail (cat. no. 539134; Calbiochem; Merck KGaA) and centrifuged at $12,000 \mathrm{x} \mathrm{g}, 4^{\circ} \mathrm{C}$ for $10 \mathrm{~min}$.

Proteins in liver tissues were extracted using $200 \mu 1$ lysis buffer containing protease and phosphatase inhibitor cocktail from 20-40 mg frozen liver tissues.

Protein concentrations were determined with BCA Protein Assay kit (cat. no. P0010; Beyotime Institute of Biotechnology). A total of $30 \mu \mathrm{g}$ protein was loaded per lane in $8 \%$ SDS-PAGE and then transferred onto PVDF membranes (cat. no. 162-0177; Bio-Rad Laboratories, Inc.), blocked with 5\% skimmed milk (cat. no. 232100; Becton, Dickinson and Company) for $2 \mathrm{~h}$ at room temperature and incubated with primary antibodies overnight at $4^{\circ} \mathrm{C}$. Membranes were then washed three times in TBST solution followed by incubation with secondary antibodies (cat. no. 1706515 or 1706516; Bio-Rad Laboratories, Inc.) for $2 \mathrm{~h}$ and visualized using Clarity Western ECL Blotting Substrates (cat. no. 170-5061; Bio-Rad Laboratories,
Table I. Real-time QPCR primers.

\begin{tabular}{|c|c|c|}
\hline Gene name & Accession no. & Primer $\left(5^{\prime}-3^{\prime}\right)$ \\
\hline \multicolumn{3}{|l|}{ Human } \\
\hline$L D L R$ & NM 000527.4 & $\begin{array}{l}\text { ctgaaatcgccgtgttactg } \\
\text { gccaatccettgtgacatct }\end{array}$ \\
\hline PCSK 9 & NM 174936.3 & $\begin{array}{l}\text { ccaagcetcttcttacttcacc } \\
\text { gcatcgttctgccatcact }\end{array}$ \\
\hline GAPDH & NM 002046.3 & $\begin{array}{l}\text { aagaaggtggtgaagcagg } \\
\text { aggtggaggagtgggtgtcg }\end{array}$ \\
\hline \multicolumn{3}{|l|}{ Hamster } \\
\hline$L D L R$ & NM 010700 & $\begin{array}{l}\text { ttgggttgattccaaactcc } \\
\text { gattggcactgaaaatggct }\end{array}$ \\
\hline PCSK 9 & NM 153565 & $\begin{array}{l}\text { tgctccagaggtcatcacag } \\
\text { gtcccactctgtgacatgaag }\end{array}$ \\
\hline GAPDH & DQ 403055 & $\begin{array}{l}\text { aactttggcattgtggaagg } \\
\text { ggatgcagggatgatgttct }\end{array}$ \\
\hline
\end{tabular}

LDLR, low-density lipoprotein receptor; PCSK9: proprotein convertase subtilisin/kexin type 9; GAPDH: glyceraldehyde-3-phosphate dehydrogenase.

Inc.). Values were normalized to the housekeeping protein $\beta$-actin. Quantity One (v4.6.2, Bio-Rad Laboratories, Inc.) was used for densitometry.

RNA interference. Small interfering RNA (siRNA; $1,500 \mathrm{ng} /$ well) was transfected into HepG2 cells in 12-well plates using Lipofectamine 3000 reagent according to the manufacturer's instructions (Invitrogen; Thermo Fisher Scientific, Inc.). At $24 \mathrm{~h}$ post transfection, cell culture medium was discarded and replaced with fresh DMEM with $10 \% \mathrm{FBS}(\mathrm{v} / \mathrm{v})$. At $24 \mathrm{~h}$ later, cells were used for subsequent experiments. siRNAs against human LDLR (forward: 5'-CGGCUUAAGAACAUCAACAdTdT-3', reverse: 5'-UGUUGAUGUUCUUAAGCCGdTdT-3') and scrambled siRNA were synthesized by Shanghai GenePharma Co., Ltd.

$R N A$ isolation and reverse transcription-quantitative (RT-q) $P C R$. Total RNA was extracted from HepG2 cells after treatment with drugs for $6 \mathrm{~h}$, or from hamster liver tissues, using TRIzol ${ }^{\circledR}$ Reagent (cat. no. 15596-018; Thermo Fisher Scientific, Inc.) and reverse transcribed into cDNA (cat. no. RR036A; Takara Biotechnology Co., Ltd.). RT-qPCR was performed using SYBR Green PCR Supermix (cat. no. 172-5125; Bio-Rad Laboratories, Inc.) with specific primers as listed in Table I. The relative signal intensity was measured by CFX Real-time PCR Detection System (Bio-Rad Laboratories, Inc.). The following thermocycling conditions were used: Initial denaturation at $95^{\circ} \mathrm{C}$ for $2 \mathrm{~min}$; followed by 40 cycles of $95^{\circ} \mathrm{C}$ for $15 \mathrm{sec}, 58^{\circ} \mathrm{C}$ for $25 \mathrm{sec}$ and $72^{\circ} \mathrm{C}$ for $25 \mathrm{sec}$. Values were normalized to the housekeeping gene GAPDH and then analyzed in Bio-Rad CFX manager (v3.0) using the mode for normalized expression $\left(2^{-\Delta \Delta \mathrm{Cq}}\right)$ (28). Results were presented as relative fold changes to the control group. 
A

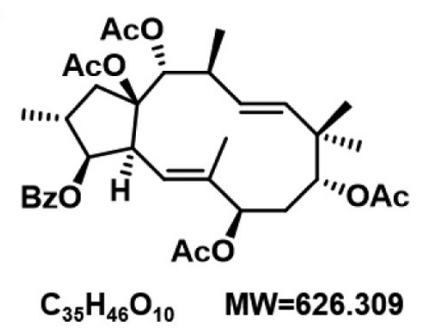

D

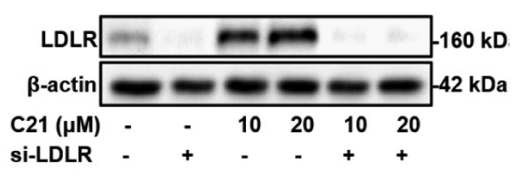

B

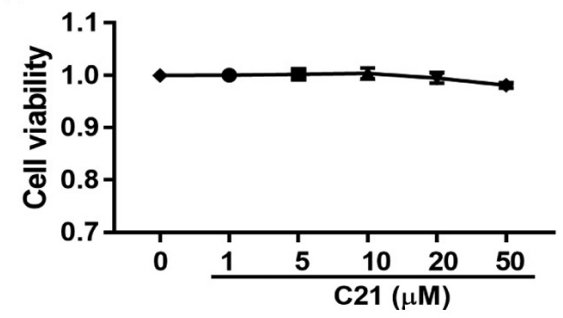

$E$

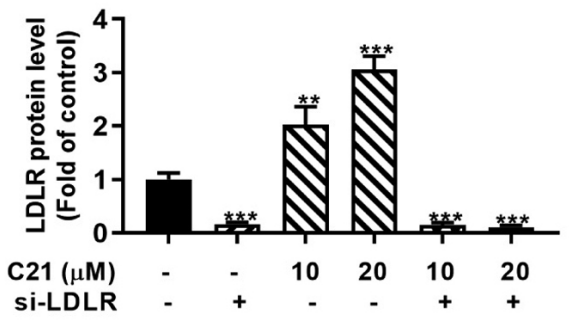

C

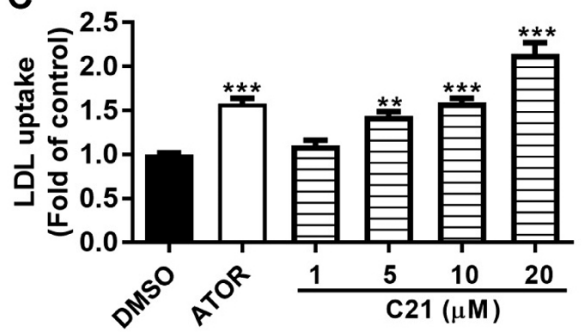

$\mathbf{F}$

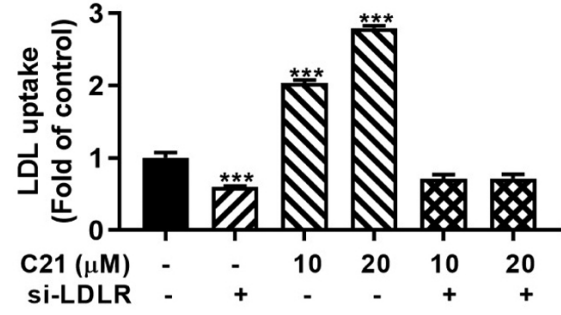

Figure 1. C21 improves LDL uptake by increasing LDLR protein levels in HepG2 cells. (A) Chemical structure of C21 (46). (B) The effect of C21 on HepG2 cell viability. (C) After treatment for $24 \mathrm{~h}, \mathrm{C} 21$ dose-dependently promoted LDL uptake in HepG2 cells. ATOR (5 $\mu$ M) was used as a positive control. (D and E) Efficacy of si-LDLR. (F) Knocking down LDLR protein by siRNA abolished the effect of C21 on LDL uptake. Results are presented as the means \pm standard error of the mean, $n \geq 5$. ${ }^{* *} \mathrm{P}<0.01,{ }^{* * * *} \mathrm{P}<0.001$ vs. vehicle control by one-way ANOVA (with Dunnett's multiple comparisons test). $\mathrm{C} 21$, euphornin L; LDL, Low density lipoprotein; LDLR, LDL receptor; ATOR, atorvastatin; si, small interfering.

Transient transfections of luciferase reporter constructs. Wildtype or mutant LDLR (gifts from Professor Lene Holland, University of Missouri School of Medicine, Columbia, MO, USA) and PCSK9 (gifts from Professor Sahng Wook Park, Yonsei University College of Medicine, Seoul, Republic of Korea) promoter reporter constructs were co-transfected with the Renilla luciferase vector (cat. no. E2231; Promega Corporation) respectively, which was constitutively expressed as a transfection control, into HepG2 cells using Lipofectamine 3000 reagent (Thermo Fisher Scientific, Inc.). At $24 \mathrm{~h}$ post transfection, cell culture medium was discarded and changed to new DMEM with $10 \%$ FBS (v/v). At $24 \mathrm{~h}$ later, cells were used for subsequent experiments. Luciferase activity was evaluated by dual-luciferase reporter assay system according to the manufacturer's instructions (cat. no. E1910; Promega Corporation). Data were normalized to Renilla luciferase activity.

$m R N A$ stability assay. HepG2 cells $\left(1 \times 10^{5}\right.$ cells/well) were cultured at $37^{\circ} \mathrm{C}$ in 24 -well plates for $12 \mathrm{~h}$ before the culture medium was then changed to 2\% LPDS DMEM (v/v). Following incubation for $24 \mathrm{~h}, \mathrm{C} 21(5$ and $20 \mu \mathrm{M})$ or DMSO were added into the medium and incubated with cells at $37^{\circ} \mathrm{C}$ for another $24 \mathrm{~h}$. Actinomycin D (cat. no. SBR00013; SigmaAldrich; Merck KGaA) was added into medium to inhibit RNA transcription in cells, as previously described (29). After incubated for predetermined time (30-180 min), cells were lysed to collect total RNA and remaining LDLR and PCSK 9 mRNA in cells was determined by RT-qPCR.

Animals and drug treatment. Our previous study evaluated the lipid-lowering effects of $\mathrm{C} 21$ (intragastric administration, i.g., $30 \mathrm{mg} / \mathrm{kg} / \mathrm{day}$ ) in high-fat diet induced hyperlipidemia Golden Syrian hamster model (24). A total of 12 male LVG golden Syrian hamsters (strain code: 501), with body weight of 80-90 g (age, 6-9 weeks), were obtained from the Beijing Vital River Laboratory Animal Technology Co., Ltd. and housed in ventilated cages under $20-26^{\circ} \mathrm{C}$, humidity of $40-70 \%$, and a 12-h light/dark cycle with free access to water. After feeding with a high-fat (HF) diet, which contained $0.5 \%$ cholesterol and $10 \%$ lard oil, the animals were separated into two groups: HF Group $(n=6)$ and C21 Group $(n=6)$, according to the serum lipid profiles. During the three weeks' treatment (D1-D21), the body weight of hamsters and lipid profiles in the serum were monitored at following time points: The day before switching food to high-fat diet, one week after switching, on the tenth day (D10) of treatment with $\mathrm{C} 21$ and at the end of the treatment (D21). To collect the blood, hamsters were anaesthetized with $2 \%$ isoflurane (30) and $300 \mu \mathrm{l}$ blood was collected via the jugular vein. At the end of the experiment (D21), hamsters were sacrificed with $\mathrm{CO}_{2}$ euthanasia followed by bilateral thoracotomy, the flow rate of $\mathrm{CO}_{2}$ used in the present study was $25 \%$ displacement of the chamber volume per minute following which the liver tissue samples were collected. All animal procedures were in compliance with PREPARE guidelines (31) and were approved by the Institutional Ethics Committee of Shanghai Institute of Materia Medica, Chinese Academy of Sciences (approval no. 2018-08-WYP-30).

In order to confirm the effects of $\mathrm{C} 21$, tissue protein lysates and total RNA were extracted from liver tissues and subjected to western blot and RT-qPCR assays respectively to assess protein and mRNA levels. The serum PCSK9 protein level and the serum ALT and AST activities were assessed with commercial kits.

ELISA. The PCSK9 protein level in serum was measured using Quantikine ${ }^{\circledR}$ ELISA kit according to the manufacturer's instructions (cat. no. MPC900; R\&D Systems, Inc.) $(32,33)$. 
A

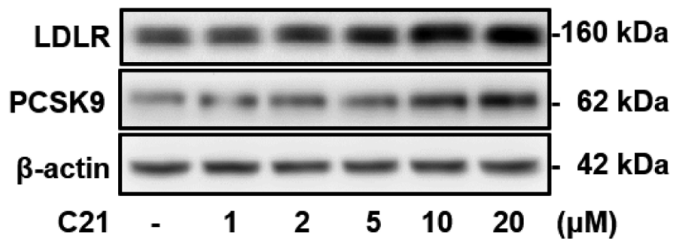

C

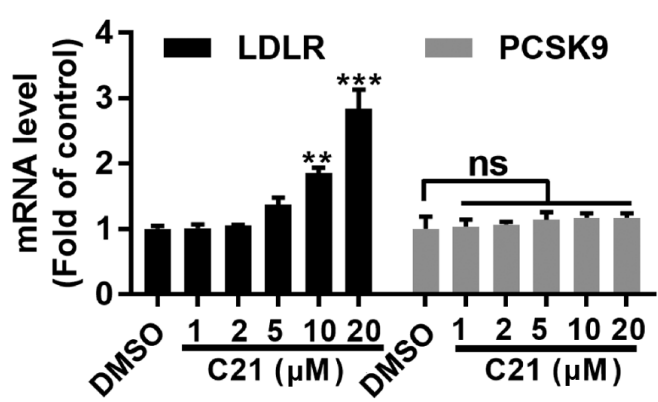

B

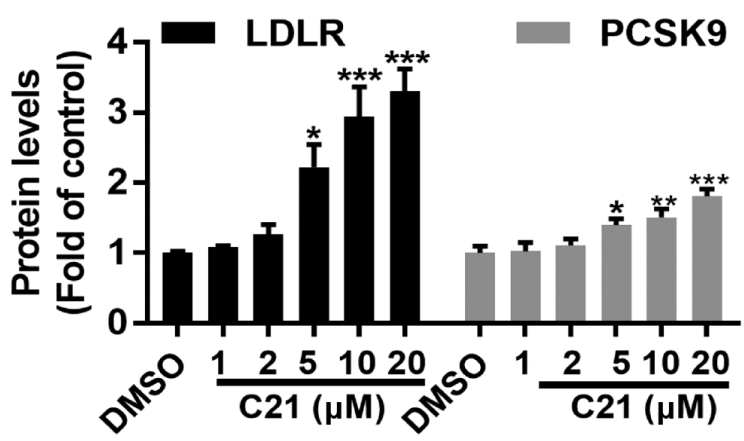

D

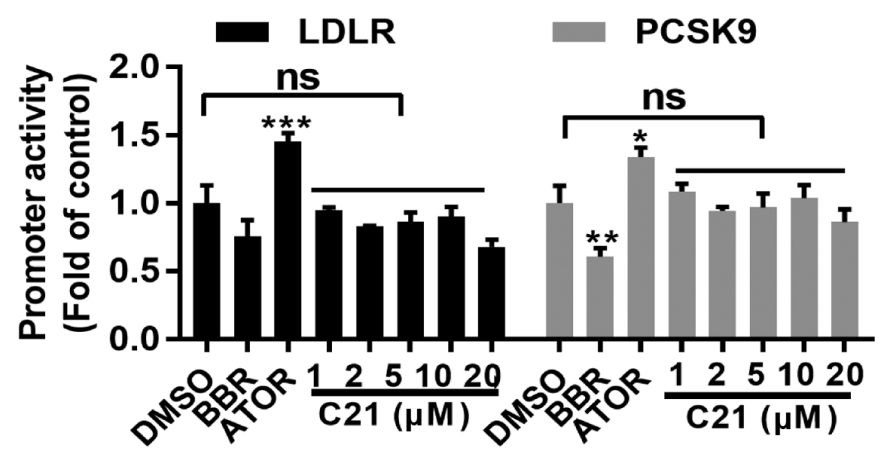

Figure 2. C21 has little effect on the promoter activities of LDLR and PCSK9. (A and B) C21 elevated LDLR and PCSK9 protein levels in HepG2 cells after treatment for $24 \mathrm{~h}$. (C) $\mathrm{C} 21$ boosted $L D L R$ mRNA levels dose-dependently after treatment for $6 \mathrm{~h}$ but had little effect on PCSK9 mRNA levels. (D) C21 induced no significant effects on $L D L R$ and PCSK 9 promoter activities. Results are presented as the means \pm standard error of the mean, $\mathrm{n} \geq 5$. ${ }^{*} \mathrm{P}<0.05,{ }^{* *} \mathrm{P}<0.01$, ${ }^{* * * *} \mathrm{P}<0.001$ vs. vehicle control by one-way ANOVA (with Dunnett's multiple comparisons test). C21, euphornin L; LDL, Low density lipoprotein; LDLR, LDL receptor; PCSK9, Proprotein convertase subtilisin/kexin type 9; BBR, berberine; ATOR, atorvastatin; ns, no significance.

Statistical analysis. For each experiment, the values were expressed as the mean \pm standard error of the mean. All data were obtained from at least three independent experiments. Statistical analysis was performed using GraphPad Prism (v7.0, GraphPad Software Inc.). Student's t-test was used to determine if two sets of data were significantly different from each other. One-way ANOVA was used to compare the statistical differences between at least three groups of data and Dunnett's multiple comparison test was used to compare all groups with the control group. $\mathrm{P}<0.05$ was considered to indicate a statistically significant difference.

\section{Results}

C21 improves LDL uptake by increasing LDLR protein levels in HepG2 cells. Since C21 (Fig. 1A) had little effect on the viability of HepG2 cells at experimental concentrations in this study (1-50 $\mu \mathrm{M}$; Fig. 1B), DiI-LDL uptake assays and western blot assays were conducted to verify the effect of C21 on LDL uptake and LDLR protein. In line with our previous study (24), C21 dose-dependently promoted DiI-LDL uptake and LDLR protein abundance in HepG2 cells (Fig. 1C-E). In addition, knocking down LDLR with a specific siRNA abolished the C21-induced increase in DiI-LDL uptake (Fig. 1D-F). These results suggested that the promotion of DiI-LDL uptake by C21 was LDLR-dependent and that C21 improved LDL uptake by increasing LDLR protein levels in HepG2 cells.
C21 has little effect on the promoter activities of LDLR and PCSK9 genes. As mentioned above, PCSK9 serves an important role in the post-translational regulation of LDLR protein. The present study further assessed whether PCSK9 was involved in C21-induced LDLR elevation in HepG2 cells using western blot assay. As expected, LDLR protein levels increased dose-dependently. Notably, PCSK9 protein levels were also dose-dependently increased in HepG2 cells after treatment with C21 (Fig. 2A and B). To further investigate the effects of $\mathrm{C} 21$ on mRNA levels and promoter activities of both $L D L R$ and PCSK9, RT-qPCR assays and dual luciferase reporter assays were conducted. It was found that $\mathrm{C} 21$ dosedependently increased $L D L R$ mRNA levels but had little effect on PCSK 9 mRNA levels (Fig. 2C). Notably, C21 induced no significant difference in the promoter activities of both $L D L R$ and PCSK9 genes (Fig. 2D). These results indicated that post-transcriptional regulation of LDLR and PCSK9 might be induced by C21 to elevate LDLR and PCSK9 protein levels in HepG2 cells.

C21 increases the half-life of LDLR $m R N A$ and reduces the PCSK 9 protein abundance in cell culture medium. Given the instability of $L D L R$ mRNA, the half-life of $L D L R$ mRNA in HepG2 cells was evaluated after treatment with C21. C21 $(20 \mu \mathrm{M})$ increased the half-life of $L D L R$ mRNA by almost 3 -fold (Fig. 3A, DMSO group, $\mathrm{T}_{1 / 2}=31.49 \mathrm{~min}$; $\mathrm{C} 21-20 \mu \mathrm{M}$ group, $\mathrm{T}_{1 / 2}=92.45 \mathrm{~min}$ ). 
A

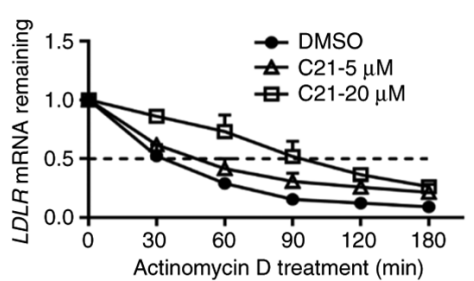

D
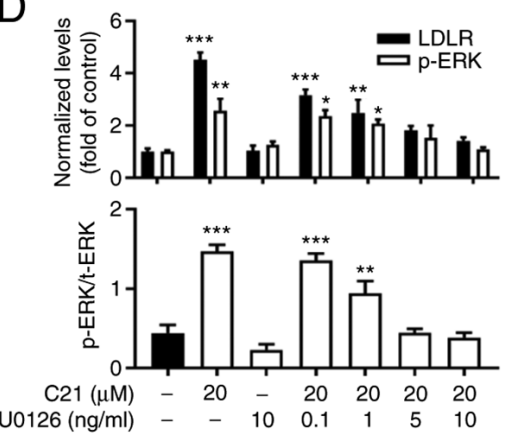

G

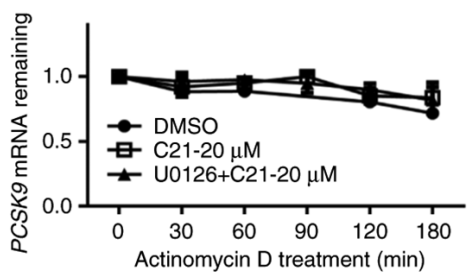

B

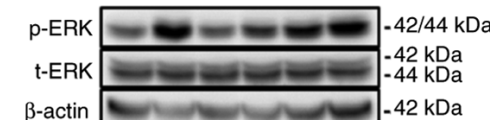

$\beta$-actin $-42 \mathrm{kDa}$
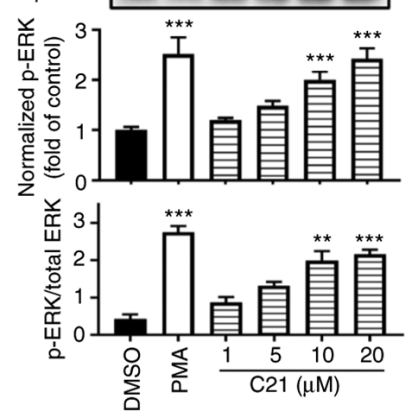

$\mathrm{E}$

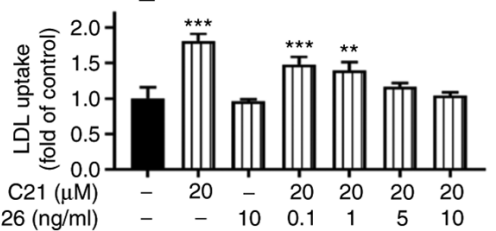

$\mathrm{H}$

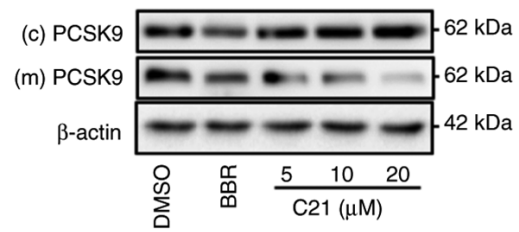

C

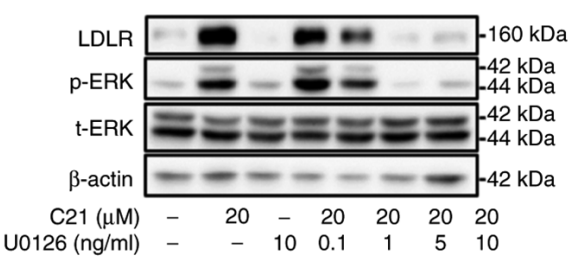

$\mathrm{F}$
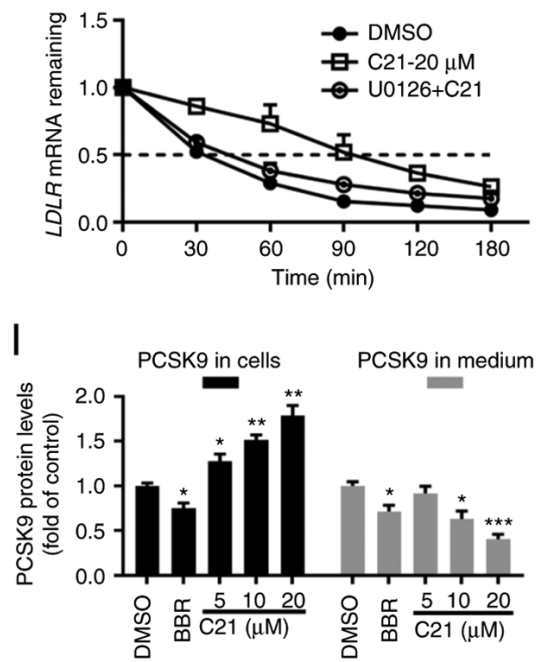

Figure 3. C21 increases the half-life of $L D L R$ mRNA and reduced the secretion of PCSK9 protein. (A) C21 increased the half-life of $L D L R$ mRNA. (B) After treatment for $2 \mathrm{~h}, \mathrm{C} 21$ dose-dependently promoted the phosphorylation of ERK protein. PMA $(5 \mathrm{ng} / \mathrm{ml})$ was used as a positive control. (C-F) The ERK activation inhibitor U0126 counteracted the effects of C21 on LDLR protein, LDL uptake and half-life of LDLR mRNA in HepG2 cells. (G) C21 had little effect on the half-life of PCSK9 mRNA. (H and I) C21 decreased the secretion of PCSK9 protein into cell culture medium. BBR (40 $\mu \mathrm{M})$ was used as a positive control. Results are presented as the means \pm standard error of the mean, $n \geq 5$. $\mathrm{P}<0.05,{ }^{* *} \mathrm{P}<0.01,{ }^{* * * *} \mathrm{P}<0.001$ vs. vehicle control by one-way ANOVA (Dunnett's multiple comparisons test). C21, euphornin L; LDL, Low density lipoprotein; LDLR, LDL receptor; PMA, phorbol 12-myristate 13-acetate; p-, phosphorylated; t-, total; PCSK9, Proprotein convertase subtilisin/kexin type 9; (c) PCSK9, PCSK9 protein in whole cell lysates; (m) PCSK9, PCSK9 protein in cell culture medium; BBR, berberine.

Since the activation of ERK protein has been found to be involved in $L D L R$ mRNA stabilization (4,14-16), the effect of C21 on ERK was assessed. The results showed that treatment with $\mathrm{C} 21$ for $2 \mathrm{~h}$ dose-dependently elevated the phosphorylation of ERK (Fig. 3B). Furthermore, when cells were pretreated with U0126, a specific inhibitor of mitogen-activated protein kinase (MAPKK or MEK), the effects of C21 on LDLR protein (Fig. 3C and D), LDL uptake (Fig. 3E) and LDLR mRNA halflife (Fig. 3F) were abolished, which demonstrated that C21 boosted LDLR expression by stabilizing $L D L R$ mRNA and the activation of ERK was essential in this post-transcriptional regulation.

C21 had little effect on the half-life of PCSK9 mRNA (Fig. 3G). However, unexpectedly, following treatment with C21 (5-20 $\mu \mathrm{M})$, PCSK9 protein levels in cell culture medium were decreased even though PCSK9 protein levels in whole cell lysates were increased. The plant-derived compound berberine, which has been reported to transcriptionally suppress PCSK9 expression in HepG2 cells (4), was used as a positive control. As $\mathrm{C} 21$ evoked little effect on the promoter activity and mRNA level of PCSK9 in HepG2 cells, it was hypothesized that C21 might inhibit the secretion of PCSK9 protein.
C21 upregulates LDLR and PCSK9 protein levels in hamster liver tissues and downregulates PCSK9 protein levels in hamster serum. Consistent with the results obtained from HepG2 cells, LDLR, PCSK9 and p-ERK protein levels as well as $L D L R$ mRNA levels in hamster liver tissues were significantly elevated ( $\mathrm{P}<0.05$ or $\mathrm{P}<0.001$, Fig. $4 \mathrm{~A}-\mathrm{C}, \mathrm{E}$ and $\mathrm{F})$. In addition, compared with the HF group, the $\mathrm{C} 21$ group showed a significant reduction in PCSK9 protein abundance in serum ( $\mathrm{P}<0.05$, Fig. 4D) but little change in PCSK9 mRNA levels in liver tissues (Fig. 4C).

In addition, treatment with $\mathrm{C} 21$ caused no obvious damage to hamster liver tissues since no significant differences in serum ALT and AST activities, nor in the food intake of hamsters, were observed between the two groups (Fig. 4G-I).

\section{Discussion}

The current study explored the mechanisms underlying the lipid-lowering effect of $\mathrm{C} 21$ in HepG2 cells. It demonstrated that C21 increased LDLR protein levels by stabilizing $L D L R$ mRNA and inhibiting the secretion of PCSK9 protein.

Following treatment with $\mathrm{C} 21$ for $6 \mathrm{~h}$, the $L D L R$ mRNA in HepG2 cells was dose-dependently increased (Fig. 2C). 
A

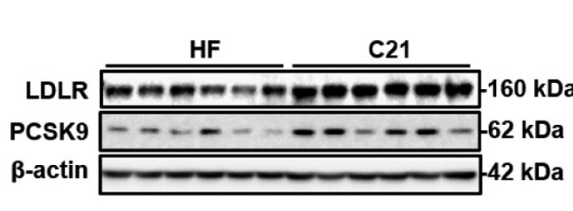

D

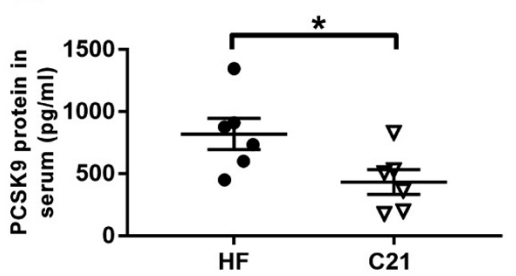

G

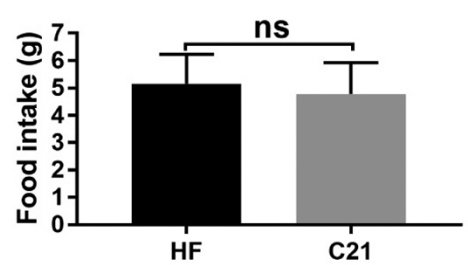

B

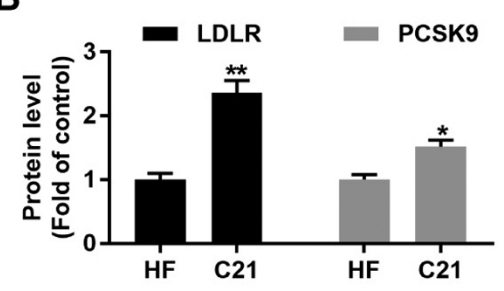

E

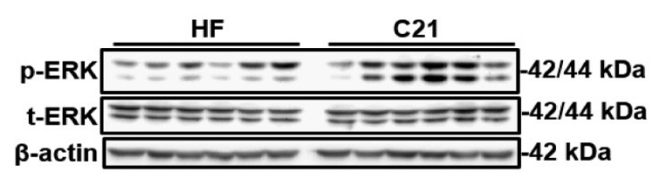

H

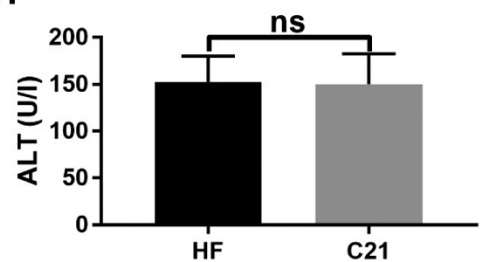

C

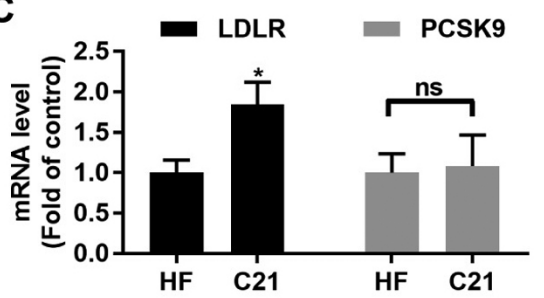

F

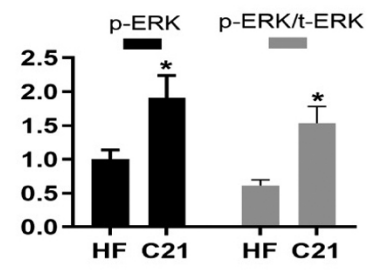

I

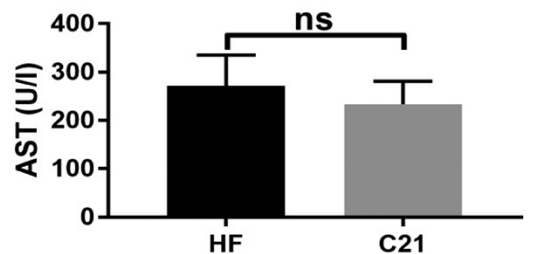

Figure 4. C21 upregulated LDLR and PCSK9 protein levels in hamster liver tissues and downregulated PCSK9 protein levels in hamster serum. (A-C) mRNA and protein levels of LDLR and PCSK9 in hamster liver tissues (n=6/group). (D) PCSK9 protein levels in hamster serum were significantly reduced after 3 weeks of treatment with C21 (30 mg/kg/d). (E and F) C21 promoted the phosphorylation of ERK protein in hamster liver tissues. (G) The food intake of hamsters in the two groups was not significantly different. (H and I) The activities of ALT and AST in hamster serum were not significantly different between the two groups. Results are presented as the means \pm standard error of the mean, $\mathrm{n}=6 .{ }^{*} \mathrm{P}<0.05,{ }^{* * *} \mathrm{P}<0.01$ vs. vehicle control by Student's t-test. C21, euphornin $\mathrm{L}$; LDL, Low density lipoprotein; LDLR, LDL receptor; PCSK9, Proprotein convertase subtilisin/kexin type 9; ALT, alanine aminotransferase; AST, aspartate aminotransferase; HF, high-fat diet; p-, phosphorylated; t-, total; ns, no significance.

However, in our previous study, HepG2 cells were treated for $24 \mathrm{~h}$ with $\mathrm{C} 21(1-10 \mu \mathrm{M})$ and the $L D L R$ mRNA levels were not significantly changed (24). It is hypothesized that $24 \mathrm{~h}$ may not be an appropriate time to assess the effects of $\mathrm{C} 21$ on $L D L R$ mRNA since the LDLR mRNA half-life was $92.45 \mathrm{~min}$ following treatment with $20 \mu \mathrm{M} \mathrm{C} 21$.

The half-life of ARE-containing mRNAs is mainly regulated by ARE-BPs (ARE binding proteins) (34). Some ARE-BPs, such as TTP, ZFP36, AUF1/hnRNP D and KSRP proteins, have been shown to promote the degradation of mRNA by binding with AREs $(35,36)$ and other ARE-BPs, such as ELAVL1/HuR protein, prolong the half-life of mRNA $(34,37)$. The activation of ERK protein has been found to be involved in $L D L R$ mRNA stabilization (4,14-16). The mechanism remains to be elucidated, but the phosphorylation of ERK may influence the binding of specific ARE-BPs, such as ZFP36L1 and ZFP36L2 (36) as well as HuR protein (37), to the SRE1 motif in the $L D L R$ promoter. The present study found that the activation of ERK protein was essential in the stabilization of LDLR mRNA induced by C21. It is planned to determine whether and which ARE-BPs are involved downstream of ERK activation in future studies.

Following treatment with C21, PCSK9 protein in HepG2 cells increased while PCSK9 protein levels in cell culture medium decreased without a significant influence on the promoter activity and mRNA level of PCSK9. Therefore, it was hypothesized that the secretion of PCSK9 might be inhibited by C21. The inhibition was confirmed when the serum PCSK9 level was decreased while the hepatocellular PCSK9 protein level was increased in hamsters from the $\mathrm{C} 21$ group. During the cellular transportation of secretory proteins, coat protein complex II, consisting of SAR1 gene homolog B (SAR1B) GTPase, SEC23/SEC24 (heterodimers) and SEC13/SEC31 (heterotetramers), is responsible in the early secretion phase from the ER to the Golgi bodies (38). It has been reported that genetic deficiency of SEC24A in mice results in decreased secretion of PCSK9 protein (39). However, SEC24A cannot interact directly with PCSK9 since the former is located outside of the ER membrane while the latter is limited to the luminal side (40). A study published in 2018 proposed that SURF4 protein, an ER cargo receptor, might serve as a primary mediator of PCSK9 in the ER, as knocking down SURF4 results in an accumulation of PCSK9 in the ER (40). Sortilin 1 (SORT1), a trans-membrane trafficking receptor localized to the transGolgi network and early endosomes (41), has been demonstrated to be significantly associated with coronary artery disease, LDL-C levels and abdominal aortic aneurysm (41-43). In 2014, Gustafsen et al (44) reported that SORT1 promotes the secretion of PCSK9. Furthermore, a SORT1 inhibitor, AF38469, decreases plasma cholesterol levels in Western diet-fed mice, suggesting that SORT1 may serve as a potential target for hyperlipidemia treatment (45). The current study found that PCSK9 protein levels in cell culture medium or hamster serum decreased after treatment with $\mathrm{C} 21$, without any significant changes in PCSK9 promoter activity or PCSK 9 mRNA levels. Thus, the secretion process of PCSK9 might be inhibited by $\mathrm{C} 21$. However, how C21 
is involved in this process remains to be elucidated, which will be attempted in future studies.

In conclusion, the present study demonstrated that euphornin L increased LDLR protein levels in HepG2 cells by dual regulation of $L D L R$ mRNA and PCSK9 and represented an active compound for lipid-lowering drug development.

\section{Acknowledgements}

TheauthorsthankProfessorJing-wenLiu(DepartmentofVeterans' Affairs, Palo Alto Health Care System) for kindly providing anti-hamster PCSK9 antibody and Professor Lene Holland (University of Missouri School of Medicine, Columbia, MO, USA) and Professor Sahng Wook Park (Yonsei University College of Medicine, Seoul, Republic of Korea) for kindly providing $L D L R$ and $P C S K 9$ promoter reporter constructs as gifts. The authors would also like to express our sincere gratitude and deep condolence to our mentor, Professor Yi-ping Wang, who passed away on April 11, 2018, for his enlightening mentoring and strong support throughout.

\section{Funding}

The authors gratefully acknowledge grants from the Drug Innovation Major Project of China (grant no. 2018ZX09735001-002-005), the Personalized MedicinesMolecular Signature-based Drug Discovery and Development Strategic Priority Research Program of the Chinese Academy of Sciences (grant no. XDA12040335), the National Natural Science Foundation of China (grant no. 81773863) and the Youth Innovation Promotion Association (grant no. 2019284).

\section{Availability of data and materials}

The datasets used and/or analyzed during the current study are available from the corresponding author on reasonable request.

\section{Authors' contributions}

LX and HL designed the study. HL, JuL and XZ performed the experiments and drafted the manuscript. JiL, CX, WW and YL were involved in data analysis and interpretation, All authors confirm the authenticity of all data. All authors have read and approved the final manuscript.

\section{Ethics approval and consent to participate}

The study was approved by the Ethics Committee of Shanghai Institute of Materia Medica (approval no. 2018-08-WYP-30) and the Ethics Committee of Shanghai Xuhui Central Hospital (approval no. 2018-038). Informed consents were signed by the healthy volunteers.

\section{Patient consent for publication}

Not applicable.

\section{Competing interests}

The authors declare that they have no competing interests.

\section{References}

1. Wadhera RK, Steen DL, Khan I, Giugliano RP and Foody JM: A review of low-density lipoprotein cholesterol, treatment strategies, and its impact on cardiovascular disease morbidity and mortality. J Clin Lipidol 10: 472-489, 2016.

2. Stone NJ, Robinson JG, Lichtenstein AH, Bairey Merz CN, Blum CB, Eckel RH, Goldberg AC, Gordon D, Levy D, Lloyd-Jones DM, et al; American College of Cardiology/ American Heart Association Task Force on Practice Guidelines: 2013 ACC/AHA guideline on the treatment of blood cholesterol to reduce atherosclerotic cardiovascular risk in adults: A report of the American College of Cardiology/American Heart Association Task Force on Practice Guidelines. Circulation 129 (Suppl 2): S1-S45, 2014.

3. Grundy SM,AraiH,BarterP,BersotTP,Betteridge DJ,Carmena R, Cuevas A, Davidson MH, Genest J, Kesäniemi YA, et al; Expert Dyslipidemia Panel of the International Atherosclerosis Society Panel members: An International Atherosclerosis Society Position Paper: Global recommendations for the management of dyslipidemia - full report. J Clin Lipidol 8: 29-60, 2014.

4. Li H, Dong B, Park SW, Lee HS, Chen W and Liu J: Hepatocyte nuclear factor 1alpha plays a critical role in PCSK9 gene transcription and regulation by the natural hypocholesterolemic compound berberine. J Biol Chem 284: 28885-28895, 2009.

5. Zhang DW, Garuti R, Tang WJ, Cohen JC and Hobbs HH: Structural requirements for PCSK9-mediated degradation of the low-density lipoprotein receptor. Proc Natl Acad Sci USA 105: 13045-13050, 2008.

6. Kesaniemi YA, Witztum JL and Steinbrecher UP: Receptormediated catabolism of low density lipoprotein in man. Quantitation using glucosylated low density lipoprotein. J Clin Invest 71: 950-959, 1983.

7. Brown MS and Goldstein JL: A receptor-mediated pathway for cholesterol homeostasis. Science 232: 34-47, 1986.

8. Lo Surdo P, Bottomley MJ, Calzetta A, Settembre EC, Cirillo A, Pandit S, Ni YG, Hubbard B, Sitlani A and Carfí A: Mechanistic implications for LDL receptor degradation from the PCSK9/ LDLR structure at neutral pH. EMBO Rep 12: 1300-1305, 2011.

9. Goldstein JL and Brown MS: A century of cholesterol and coronaries: From plaques to genes to statins. Cell 161: 161-172, 2015.

10. Südhof TC, Van der Westhuyzen DR, Goldstein JL, Brown MS and Russell DW: Three direct repeats and a TATA-like sequence are required for regulated expression of the human low density lipoprotein receptor gene. J Biol Chem 262: 10773-10779, 1987.

11. Miserez AR, Muller PY, Barella L, Barella S, Staehelin HB, Leitersdorf E, Kark JD and Friedlander Y: Sterol-regulatory element-binding protein (SREBP)-2 contributes to polygenic hypercholesterolaemia. Atherosclerosis 164: 15-26, 2002.

12. Wilson GM, Vasa MZ and Deeley RG: Stabilization and cytoskeletal-association of LDL receptor mRNA are mediated by distinct domains in its 3' untranslated region. J Lipid Res 39: 1025-1032, 1998

13. Zhang T, Kruys V, Huez G and Gueydan C: AU-rich elementmediated translational control: complexity and multiple activities of trans-activating factors. Biochem Soc Trans 30: 952-958, 2002.

14. Kong W, Wei J, Abidi P, Lin M, Inaba S, Li C, Wang Y, Wang Z, $\mathrm{Si} \mathrm{S}$, Pan H, et al: Berberine is a novel cholesterol-lowering drug working through a unique mechanism distinct from statins. Nat Med 10: 1344-1351, 2004.

15. Yashiro T, Yokoi Y, Shimizu M, Inoue J and Sato R: Chenodeoxycholic acid stabilization of LDL receptor mRNA depends on 3'-untranslated region and AU-rich element-binding protein. Biochem Biophys Res Commun 409: 155-159, 2011.

16. Li Z, Jiang JD and Kong WJ: Berberine up-regulates hepatic low-density lipoprotein receptor through Ras-independent but AMP-activated protein kinase-dependent Raf-1 activation. Biol Pharm Bull 37: 1766-1775, 2014.

17. Zhang CP, Tian Y, Zhang M, Tuo QH, Chen JX and Liao DF: IDOL, inducible degrader of low-density lipoprotein receptor, serves as a potential therapeutic target for dyslipidemia. Med Hypotheses 86: 138-142, 2016.

18. Tavori H, Fan D, Blakemore JL, Yancey PG, Ding L, Linton MF and Fazio S: Serum proprotein convertase subtilisin/kexin type 9 and cell surface low-density lipoprotein receptor: Evidence for a reciprocal regulation. Circulation 127: 2403-2413, 2013.

19. Abifadel M, Varret M, Rabès JP, Allard D, Ouguerram K, Devillers M, Cruaud C, Benjannet S, Wickham L, Erlich D, et al: Mutations in PCSK9 cause autosomal dominant hypercholesterolemia. Nat Genet 34: 154-156, 2003. 
20. Horton JD, Cohen JC and Hobbs HH: PCSK9: A convertase that coordinates LDL catabolism. J Lipid Res 50 (Suppl): S172-S177, 2009.

21. McNutt MC, Kwon HJ, Chen C, Chen JR, Horton JD and Lagace TA: Antagonism of secreted PCSK 9 increases low density lipoprotein receptor expression in HepG2 cells. J Biol Chem 284: 10561-10570, 2009.

22. Raal FJ, Stein EA, Dufour R, Turner T, Civeira F, Burgess L, Langslet G, Scott R, Olsson AG, Sullivan D, et al, RUTHERFORD-2 Investigators: PCSK9 inhibition with evolocumab (AMG 145) in heterozygous familial hypercholesterolaemia (RUTHERFORD-2): A randomised, double-blind, placebo-controlled trial. Lancet 385: 331-340, 2015.

23. Robinson JG, Farnier M, Krempf M, Bergeron J, Luc G Averna M, Stroes ES, Langslet G, Raal FJ, El Shahawy M, et al; ODYSSEY LONG TERM Investigators: Efficacy and safety of alirocumab in reducing lipids and cardiovascular events. $N$ Engl J Med 372: 1489-1499, 2015.

24. Li J, Li HH, Wang WQ, Song WB, Wang YP and Xuan LJ: Jatrophane diterpenoids from Euphorbia helioscopia and their lipid-lowering activities. Fitoterapia 128: 102-111, 2018.

25. Yamamura S, Shizuri Y, Kosemura S, Ohtsuka J, Tayama T, Ohba S, Ito M, Saito Y and Terada Y: Diterpenes from Euphorbia helioscopia. Phytochemistry 28: 3421-3436, 1989.

26. World Med A; World Medical Association: World Medical Association Declaration of Helsinki: Ethical principles for medical research involving human subjects. JAMA 310 2191-2194, 2013

27. Stephan ZF and Yurachek EC: Rapid fluorometric assay of LDL receptor activity by DiI-labeled LDL. J Lipid Res 34: 325-330, 1993.

28. Livak KJ and Schmittgen TD: Analysis of relative gene expression data using real-time quantitative PCR and the 2(-Delta Delta C(T)) Method. Methods 25: 402-408, 2001

29. Sobell HM: Actinomycin and DNA transcription. Proc Natl Acad Sci USA 82: 5328-5331, 1985.

30. Greenfield EA: Administering anesthesia to mice, rats, and hamsters. Cold Spring Harb Protoc: Jun 3, 2019. doi: 10.1101/ pdb.prot100198.

31. Smith AJ, Clutton RE, Lilley E, Hansen KEA and Brattelid T: PREPARE: Guidelines for planning animal research and testing. Lab Anim 52: 135-141, 2018.

32. Dong B, Young M, Liu X, Singh AB and Liu J: Regulation of lipid metabolism by obeticholic acid in hyperlipidemic hamsters. J Lipid Res 58: 350-363, 2017.

33. Dong B, Li H, Singh AB, Cao A and Liu J: Inhibition of PCSK9 transcription by berberine involves down-regulation of hepatic HNF1 $\alpha$ protein expression through the ubiquitin-proteasome degradation pathway. J Biol Chem 290: 4047-4058, 2015.

34. Barreau C, Paillard L and Osborne HB: AU-rich elements and associated factors: Are there unifying principles? Nucleic Acids Res 33: 7138-7150, 2006.
35. Wilusz CJ and Wilusz J: Bringing the role of mRNA decay in the control of gene expression into focus. Trends Genet 20: 491-497, 2004.

36. Adachi S, Homoto M, Tanaka R, Hioki Y, Murakami H, Suga H, Matsumoto M, Nakayama KI, Hatta T, Iemura S, et al: ZFP36L1 and ZFP36L2 control LDLR mRNA stability via the ERK-RSK pathway. Nucleic Acids Res 42: 10037-10049, 2014.

37. Yashiro T, Nanmoku M, Shimizu M, Inoue J and Sato R: 5-Aminoimidazole-4-carboxamide ribonucleoside stabilizes low density lipoprotein receptor mRNA in hepatocytes via ERK-dependent HuR binding to an AU-rich element. Atherosclerosis 226: 95-101, 2013.

38. Zhang Q, Meng F, Chen S, Plouffe SW, Wu S, Liu S, Li X, Zhou R, Wang J, Zhao B, et al: Hippo signalling governs cytosolic nucleic acid sensing through YAP/TAZ-mediated TBK1 blockade. Nat Cell Biol 19: 362-374, 2017.

39. Miller E, Antonny B, Hamamoto S and Schekman R: Cargo selection into COPII vesicles is driven by the Sec24p subunit. EMBO J 21: 6105-6113, 2002.

40. Emmer BT, Hesketh GG, Kotnik E, Tang VT, Lascuna PJ, Xiang J, Gingras AC, Chen XW and Ginsburg D: The cargo receptor SURF4 promotes the efficient cellular secretion of PCSK9. eLife 7: 7,2018.

41. Willnow TE, Petersen CM and Nykjaer A: VPS10P-domain receptors - regulators of neuronal viability and function. Nat Rev Neurosci 9: 899-909, 2008

42. Kathiresan S, Melander O, Guiducci C, Surti A, Burtt NP, Rieder MJ, Cooper GM, Roos C, Voight BF, Havulinna AS, et al: Six new loci associated with blood low-density lipoprotein cholesterol, high-density lipoprotein cholesterol or triglycerides in humans. Nat Genet 40: 189-197, 2008.

43. Linsel-Nitschke P, Heeren J, Aherrahrou Z, Bruse P, Gieger C, Illig T, Prokisch H, Heim K, Doering A, Peters A, et al: Genetic variation at chromosome 1p13.3 affects sortilin mRNA expression, cellular LDL-uptake and serum LDL levels which translates to the risk of coronary artery disease. Atherosclerosis 208: 183-189, 2010.

44. Gustafsen C, Kjolby M, Nyegaard M, Mattheisen M, Lundhede J, Buttenschøn H, Mors O, Bentzon JF, Madsen P, Nykjaer A, et al: The hypercholesterolemia-risk gene SORT1 facilitates PCSK9 secretion. Cell Metab 19: 310-318, 2014.

45. Chen C, Li J, Matye DJ, Wang Y and Li T: Hepatocyte sortilin 1 knockout and treatment with a sortilin 1 inhibitor reduced plasma cholesterol in Western diet-fed mice. J Lipid Res 60: 539-549, 2019.

46. Barile E, Borriello M, Di Pietro A, Doreau A, Fattorusso C, Fattorusso E and Lanzotti V: Discovery of a new series of jatrophane and lathyrane diterpenes as potent and specific P-glycoprotein modulators. Org Biomol Chem 6: 1756-1762, 2008. 